\title{
ANALISIS TINGKAT KAPASITAS DAN STRATEGI COPING MASYARAKAT LOKAL DALAM MENGHADAPI BENCANA LONGSOR- STUDI KASUS DI TAWANGMANGU, KARANGANYAR, JAWA TENGAH (Analysis of Coping Strategies and The Level of Local Community's Capacity Towards Landslide- A Case Study in Tawangmangu, Karanganyar, Central Java)
}

\author{
Heru Setiawan ${ }^{1}$ \\ ${ }^{1}$ Balai Penelitian Kehutanan Makassar \\ Jl. P. Kemerdekaan Km 16,5 Makassar, Telp./Fax. (0411) 554049/554051, \\ E-mail: hiero_81@yahoo.com
}

Diterima 4 November 2013, direvisi 6 Februari 2014, disetujui 28 Februari 2014

\begin{abstract}
Landslide was occurred in 2007 at Tawangmangu resulting collapse of dozens houses and killing of dozenspeople. Analysis of community's capacity to landslides is essential elements to determine the level of community's preparedness to landslides occurring in the future. Analysis influencing factors of community's capacity should be known to develop appropriate policies and mitigation action for dealing with landslide. This research was conducted at Tengklik. Village and Tawangmangu Village, Tawangmangu Sub-district, Karanganyar Regency. This research was aimed to identify various coping strategy that be done by local community and to assess the level of community's coping capacity related to landslide. Survey method with random sampling technique was applied to assess the level of community's capacity related to landslide. The number of respondents is 93 spreadproportionally across five sub-villages; Plalar, Guyon, Sodong and Salere in Tengklik and Ngledoksari in Tawangamngu Village. The respondents were interviewed using questionnaires with open and closed questions. Statistical analysis was applied to identify the influencing factors of community's capacity related to landside. Local people applied three type coping strategy, which are: economic, structural, social and cultural coping strategy. Totally, 52\% respondents have high level capacity, 33\% have moderate level and only 15\% respondents that have low level of capacity. The factors that influence the level of capacity are education, income and building type.
\end{abstract}

Keywords: Landslide, coping strategy, level of capacity, Tawangmangu

\begin{abstract}
ABSTRAK
Longsor di Kecamatan Tawangmangu Kabupaten Karanganyar pada tahun 2007 mengakibatkan puluhan rumah rusak dan puluhan nyawa melayang. Analisis tingkat kapasitas masyarakat dalam menghadapi bencana longsor merupakan elemen penting untuk mengetahui tingkat kesiapsiagaan masyarakat dalam menghadapi bencana longsor yang akan terjadi di masa mendatang dan untuk meminimalkan dampak negatif yang timbul akibat bencana longsor. Penelitian ini dilakukan di Desa Tengklik dan Desa Tawangmangu Kecamatan Tawangmangu Kabupaten Karanganyar. Tujuan penelitian ini adalah untuk mengidentifikasi strategi coping yang dilakukan masyarakat lokal dan menilai tingkat kapasitas masyarakat lokal dalam menghadapi bencana longsor. Metode survei dengan pemilihan responden yang dilakukan secara acak, diaplikasikan untuk mengetahui jenis-jenis staregi coping dan tingkat kapasitas masyarakat terhadap bencana longsor. Jumlah responden sebanyak 93 orang ditentukan secara proporsional dan tersebar di lima dusun, yaitu Dusun Plalar, Guyon, Sodong dan Salere di Desa Tengklik dan Dusun Ngledoksari di Desa Tawangmangu. Wawancara terhadap responden dilakukan dengan menggunakan kuesioner dengan tipe pertanyaan terbuka dan tertutup. Masyarakat lokal menerapkan empat tipe strategi coping, yaitu ekonomi, struktural, sosial dan kultural. Terdapat 51,6\% responden mempunyai tingkat kapasitas yang tinggi, 33,3\% berada pada tingkat sedang dan hanya 15,1\% yang berada pada tingkat rendah. Faktor yang berpengaruh terhadap tingkat kapasitas masyarakat adalah tingkat pendidikan, penghasilan dan tipe rumah.
\end{abstract}

Kata kunci: Bencana longsor, strategi coping, tingkat kapasitas, Tawangmangu 


\section{PENDAHULUAN}

Bencana tanah longsor merupakan jenis bencana geologi yang sering terjadi di Indonesia. Menurut Sutikno (1994) tanah longsor atau sering disebut dengan gerakan massa tanah adalah proses perpindahan atau pergerakan massa tanah dengan arah miring atau vertikal dari kedudukan semula sebagai akibat gaya berat. Longsor dapat terjadi jika intensitas curah hujan tinggi, kondisi lereng yang miring hingga terjal, pelapukan tebal, batuan dan struktur geologi bervariasi dan penggunaan lahan yang kurang sesuai dengan karakteristik lahannya. Bencana longsor menempati peringkat ke-lima dari keseluruhan jumlah kejadian bencana yang sering terjadi di Indonesia dengan rata-rata jumlah kejadian 92 kali per tahun (Karnawati et al., 2012). Selama kurun waktu 15 tahun, yaitu dari tahun 1990 sampai dengan 2005, jumlah kejadian longsor di Pulau Jawa sebanyak 1.500 kali (Hadmoko et al., 2010).

Bencana tanah longsor tidak hanya mengakibatkan kerugian dari segi sosial dan ekonomi, tetapi juga kematian. Data yang diterbitkan oleh BNPB (2013), menyatakan bahwa jumlah korban jiwa akibat bencana longsor dari tahun 2000 sampai 2012 mencapai 204 jiwa, korban luka-luka mencapai 196 jiwa, korban hilang mencapai 74 jiwa dan korban yang mengungsi mencapai 2.780 jiwa.

Karanganyar adalah salah satu kabupaten di Propinsi Jawa Tengah yang sering mengalami bencana longsor. Data yang diterbitkan oleh BPBD Karanganyar (2012) menyatakan bahwa, selama tahun 2011 tercatat kejadian bencana longsor 34 kejadian, angin puting beliung 15 kejadian, banjir 3 kejadian dan kebakaran 29 kali. Data tersebut menunjukkan bahwa bencana utama yang paling sering terjadi di Kabupaten Karanganyar adalah tanah longsor. Salah satu kecamatan di Karanganyar yang rawan terhadap bencana longsor adalah Kecamatan Tawangmangu.

Kecamatan Tawangmangu terletak di lereng Gunung Lawu yang mempunyai puncak ketinggian $3.265 \mathrm{~m}$ diatas permukaan laut (dpl). Kondisi ini membuat sebagian besar wilayah Tawangmangu $(65 \%)$ mempunyai tingkat kelerengan lebih dari $35 \%$ dan hal inilah yang membuat $85,1 \%$ wilayah Kecamatan Tawangmangu termasuk dalam kategori kerawanan longsor tingkat sedang hingga tinggi (Wati et al., 2010). Kejadian longsor terbesar di Kecamatan Tawangmangu terjadi pada tahun 2007 di Desa Tengklik dan Desa Tawangmangu. Longsor yang terjadi di Desa Tengklik mengakibatkan 33 rumah roboh dan longsor di Desa Tawangmangu mengakibatkan 34 orang meninggal dunia (Prawiradisastra, 2008).

Untuk mengurangi kerugian yang timbul akibat bencana longsor, pemerintah dengan stakeholder yang lain melaksanakan program mitigasi bencana longsor. Masyarakat Tawangmangu yang tinggal pada daerah rawan longsor mempunyai strategi dalam menghadapi bencana longsor. Pengetahuan penduduk lokal tentang mitigasi bencana tanah longsor terbentuk dari pola pikir penduduk yang tinggal di daerah dengan kondisi lingkungan yang rawan terhadap longsor. Kondisi tersebut menyebabkan penduduk memiliki kemampuan untuk menghadapi bencana tanah longsor berdasarkan pengalaman menghadapi bencana longsor di waktu lampau (Sare, 2009). Identifikasi terhadap strategi coping masyarakat menghadapi longsor penting dilakukan agar program mitigasi bencana longsor yang dilakukan pemerintah tidak tumpang tindih dan dapat sejalan dengan keinginan masyarakat setempat. Strategi coping didefinisikan sebagai usaha dan perilaku masyarakat, baik terlihat atau tersembunyi yang dilakukan dengan maksud mengurangi ketegangan psikologi akibat sesuatu hal, dalam hal ini karena adanya ancaman bahaya bencana tanah longsor (Yani, 1997).

Kapasitas didefinisikan sebagai suatu kombinasi dari semua kekuatan yang ada pada suatu kelompok masyarakat, sosial atau organisasi yang dapat mengurangi dampak dari suatu resiko atau dampak dari suatu bencana (UN-ISDR, 2004). Penelitian mengenai tingkat kapasitas masyarakat dalam menghadapi bencana sangat penting dilakukan, sebagai upaya pencegahan terhadap timbulnya kerugian material maupun korban jiwa akibat bencana. Penelitian ini bertujuan untuk (i) mengidentifikasi strategi coping yang dilakukan masyarakat lokal dalam menghadapi bencana longsor, (ii) mengetahui tingkat kapasitas masyarakat lokal dalam menghadapi bencana longsor dan (iii) mengetahui faktor-faktor yang mempengaruhi tingkat kapasitas masyarakat lokal terhadap bencana longsor. 


\section{METODE PENELITIAN}

\section{A. Waktu dan Lokasi Penelitian}

Pengumpulan data primer pada penelitian ini dilaksanakan pada bulan Agustus sampai dengan Oktober 2012, sedangkan pengolahan dan analisis data dilaksanakan pada bulan November 2012. Lokasi penelitian terletak di Kecamatan Tawangmangu, Kabupaten Karanganyar, Jawa Tengah.

Secara administratif, Kecamatan Tawangmangu dibatasi oleh Kecamatan Ngargoyoso di sebelah utara, Kecamatan Jatiyoso di sebelah selatan, sebelah barat di batasi oleh Kecamatan Karangpandan dan Matesih dan sebelah timur berbatasan langsung dengan Kabupaten Magetan, Propinsi Jawa Timur. Berdasarkan data BPS (2012), Tawangmangu terbagi menjadi 10 desa/kelurahan, 41 dusun, 86 dukuh, 99 RW dan 345 RT.

Berdasarkan peta tingkat kerawanan longsor (Wati et al., 2010), sebagian besar daerah Kecamatan Tawangmangu termasuk dalam kategori kerawanan tingkat sedang dengan luas area 2.674,888 ha $(42,7 \%)$, kelas kerawanan tingkat tinggi dengan luas area $2.332,051$ ha $(37,3 \%)$, kelas kerawanan tingkat rendah dengan luasan 909,222 ha (14,5\%), tingkat kerawanan sangat tinggi seluas 321,839 ha (5.1\%) dan tingkat kerawanan sangat rendah seluas 21,02 ha $(0.3 \%)$.

\section{B. Alat dan Bahan}

Alat yang digunakan dalam pengambilan data primer di lapangan meliputi Global Positioning System (GPS), alat perekam, kamera digital, lembar kuesioner, panduan wawancara, alat tulis dan buku catatan. Alat yang digunakan dalam proses pengolahan data adalah seperangkat komputer dengan perangkat lunak Microsoft Office 2007 (Word, Excel) dan SPSS 19 untuk analisis statistik. Bahan pendukung penelitian diantaranya adalah peta tematik Kecamatan Tawangmangu, citra satelit resolusi tinggi dan data-data sekunder yang diperoleh dari beberapa instansi di Kabupaten Karanganyar.

\section{Metode Pengambilan Data}

Pemilihan contoh penelitian dilakukan menggunakan teknik simple random sampling, dengan unit analisis rumah tangga dankepala rumah tangga dipilih sebagai responden. Contoh penelitian dipilih di empat dusun di Desa Tengklik, yaitu Plalar, Guyon, Sodong dan Salere dan satu dusun di Desa Tawangmangu, yaitu Dusun Ngledoksari dengan pertimbangan kejadian bencana longsor terbesar pada tahun 2007 terjadi di dua desa tersebut, sehingga responden diharapkan memberikan gambaran hasil yang sesuai dengan tujuan penelitian. Jumlah keluarga di lokasi penelitian adalah 1.411 keluarga. Penentuan jumlah responden dilakukan berdasarkan formula Sugiyono (2007).

$$
S=\frac{N \cdot P \cdot Q \cdot \lambda^{2}}{d^{2}(N-1)+P \cdot Q \cdot \lambda^{2}}
$$

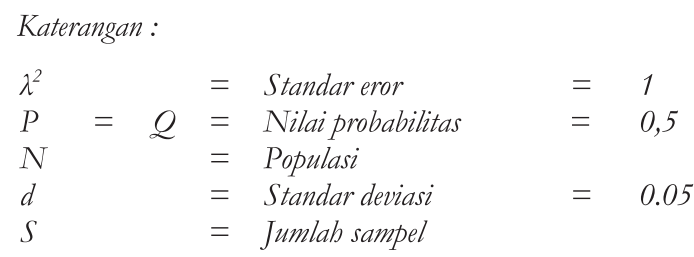

Berdasarkan formula Sugiyono (2007), jumlah responden minimal yang harus diambil adalah 93 responden. Responden terdistribusi secara proporsional pada tiap dusun sesuai dengan jumlah keluarga di masing-masing dusun. Berdasarkan perhitungan menggunakan formula tersebut, jumlah responden di masing-masing dusun adalah Dusun Plalar 14 responden, Dusun Guyon 16 responden, Dusun Sodong 25 responden, Dusun Salere 22 responden, dan Dusun Ngledoksari 16 responden.

Pengambilan data primer dilakukan dengan menggunakan alat bantu kuesioner dan in-depth interview dengan responden kunci. Kuesioner terdiri dari 11 pertanyaan tertutup dan terbuka serta 11 pertanyaan tentang karakteristik responden. Pertanyaan terbuka digunakan untuk menggali informasi dari responden berkaitan dengan upaya strategi coping yang dilakukan masyarakat dalam menghadapi longsor, sedangkan pertanyaan tertutup digunakan untuk mengukur tingkat kapasitas responden dalam menghadapi bencana longsor. Dalam pertanyaan tertutup terdapat lima pilihan jawaban, yaitu sangat setuju, setuju, ragu-ragu, tidak setuju, dan sangat tidak setuju. Jawaban pada pertanyaan tertutup dianalisis menggunakan skala Linkert dengan memberikan skor 5 (lima) jika jawaban pertanyaannya "sangat setuju" sampai dengan 1 (satu) jika jawaban 
pertanyaannya "sangat tidak setuju" (Albaum, 1997).

\section{Analisis Data}

Data primer dari lapangan ditabulasikan dengan menggunakan Microsoft Excel. Untuk memudahkan proses analisis statistik, sebelum dilakukan proses pengolahan data, terlebih dahulu dilakukan pemberian skor pada parameter karakteristik responden yang meliputi umur, jenis kelamin, tingkat pendidikan, mata pencaharian, jumlah penghasilan, jumlah anggota keluarga, tipe bangunan rumah dan pengalaman terhadap longsor. Pemberian skor ini dimaksudkan untuk memudahkan dalam pengolahan data statistik. Skor ini kemudian dijumlahkan untuk mendapatkan skor gabungan. Selanjutnya skor gabungan dibagi menjadi tiga kelas untuk mendapatkan tingkat kapasitas masyarakat yaitu : rendah, sedang dan tinggi. Analisis data dilakukan dengan menggunakan Software SPSS 19. Metode analisis yang digunakan adalah analisis statistik diskriptif, analisi korelasi, analisis chi-square dan regresi linear berganda.

\section{HASIL DAN PEMBAHASAN}

\section{A. Karakteristik Responden}

Jumlah responden secara keseluruhan adalah 93 orang yang terdiri atas $69 \%$ laki-laki dan 31\% perempuan. Umur responden berkisar antara 23 tahun sampai dengan 82 tahun. Distribusi responden berdasarkan kelas umurnya tercantum pada Tabel 1.

Berdasarkan data yang tersaji pada Tabel 1 dapat dlihat bahwa sebagian besar responden $(91,4 \%)$ termasuk dalam kelompok umur produktif, sedangkan sisanya $(8,6 \%)$ termasuk dalam kelas umur non-produktif tua. Berdasarkan penghasilan per bulan, $48 \%$ responden berpenghasilan kurang dari Rp 846.000,-/bulan, sedangkan 52\% berpenghasilan lebih dari Rp 846.000,-/bulan. Besaran penghasilan tersebut didasarkan pada upah minimum regional untuk Kabupaten Karanganyar Tahun 2012 sebesar Rp 846.000,/bulan. Berdasarkan tingkat pendidikannya, 55\% responden hanya berpendidikan sampai sekolah dasar atau dibawah sekolah dasar, 23\% responden lulus sekolah menengah pertama, $17 \%$ responden lulus sekolah menengah atas, dan 5\% responden adalah lulusan perguruan tinggi. Terkait dengan jenis mata pencaharian, distribusi responden berdasarkan jenis pekerjaannya dapat dilihat pada Tabel 2.

Berdasarkan hasil tabulasi pada Tabel 2, dapat dilihat bahwa 46\% responden bermatapencaharian sebagai petani, $11 \%$ responden pedagang, 4\% responden pegawai negeri sipil, $20 \%$ pegawai perusahaan/swasta dan $18 \%$ responden tidak mempunyai pekerjaan tetap. Responden yang tidak mempunyai pekerjaan tetap biasanya bekerja secara musiman, jika musim menggarap kebun tiba mereka berprofesi sebagai petani, dan jika tidak sedang menggarap kebun mereka berprofesi sebagai tukang batu atau pedagang bunga.

Tabel 1. Distribusi umur responden berdasarkan kelas umur angkatan kerja

Table 1. Distribution of respondents based on working age class

\begin{tabular}{|c|c|c|c|c|c|c|c|c|c|}
\hline \multirow{3}{*}{ No. } & \multirow{3}{*}{$\begin{array}{c}\text { Dusun } \\
\text { (Sub-Village) }\end{array}$} & \multicolumn{6}{|c|}{ Kelas umur angkatan kerja (Working age class) } & \multirow{2}{*}{\multicolumn{2}{|c|}{$\begin{array}{l}\text { Jumlah } \\
\text { (Total) }\end{array}$}} \\
\hline & & \multicolumn{2}{|c|}{$\begin{array}{l}\text { Non produktif muda } \\
\text { /Young non productive } \\
(<15 \text { th })\end{array}$} & \multicolumn{2}{|c|}{$\begin{array}{l}\text { Produktif /productive } \\
\qquad \text { (15-64 th) }\end{array}$} & \multicolumn{2}{|c|}{$\begin{array}{l}\text { Non produktif tua } \\
\text { /Old non productive } \\
\text { (>64 th })\end{array}$} & & \\
\hline & & $\sum$ & $\%$ & $\sum$ & $\%$ & $\sum$ & $\%$ & $\sum$ & $\%$ \\
\hline 1 & Guyon & 0 & 0 & 15 & 93.8 & 1.0 & 6.3 & 16.0 & 100.0 \\
\hline 2 & Plalar & 0 & 0 & 14 & 100.0 & 0.0 & 0.0 & 14.0 & 100.0 \\
\hline 3 & Salere & 0 & 0 & 19 & 86.4 & 3.0 & 13.6 & 22.0 & 100.0 \\
\hline 4 & Sodong & 0 & 0 & 23 & 92.0 & 2.0 & 8.0 & 25.0 & 100.0 \\
\hline \multirow[t]{2}{*}{5} & Ngledoksari & 0 & 0 & 14 & 87.5 & 2.0 & 12.5 & 16.0 & 100.0 \\
\hline & Jumlah & 0 & 0 & 85 & 91.4 & 8.0 & 8.6 & 93.0 & 100.0 \\
\hline
\end{tabular}


Tabel 2. Distribusi umur responden berdasarkan jenis pekerjaan

Table 2. Distribution of respondents based on occupation type

\begin{tabular}{|c|c|c|c|c|c|c|c|c|c|c|c|c|c|}
\hline \multirow{3}{*}{ No. } & \multirow{3}{*}{$\begin{array}{c}\text { Dusun } \\
\text { (Sub-Village) }\end{array}$} & \multicolumn{10}{|c|}{ Jenis mata pencaharian (Occupation type) } & \multirow{2}{*}{\multicolumn{2}{|c|}{$\begin{array}{l}\text { Jumlah } \\
\text { (Total) }\end{array}$}} \\
\hline & & \multicolumn{2}{|c|}{$\begin{array}{l}\text { Petani } \\
\text { (Farmer) }\end{array}$} & \multicolumn{2}{|c|}{$\begin{array}{l}\text { Pedagang } \\
\text { (Trader) }\end{array}$} & \multicolumn{2}{|c|}{$\begin{array}{c}\text { Pegawai } \\
\text { negeri } \\
\text { (Civil servant) }\end{array}$} & \multicolumn{2}{|c|}{$\begin{array}{c}\text { Pekerja swasta } \\
\text { (Private } \\
\text { employees) }\end{array}$} & \multicolumn{2}{|c|}{$\begin{array}{c}\text { Pekerjaan } \\
\text { lain (Others) }\end{array}$} & & \\
\hline & & $\sum$ & $\%$ & $\sum$ & $\%$ & $\sum$ & $\%$ & $\sum$ & $\%$ & $\sum$ & $\%$ & $\sum$ & $\%$ \\
\hline 1 & Guyon & 13.0 & 81.3 & 1.0 & 6.3 & 0 & 0 & 0 & 0 & 2 & 12.5 & 16.0 & 100.0 \\
\hline 2 & Plalar & 5.0 & 35.7 & 1.0 & 6.3 & 0 & 0 & 1 & 6.25 & 7 & 43.75 & 14.0 & 100.0 \\
\hline 3 & Salere & 9.0 & 40.9 & 2.0 & 12.5 & 2 & 12.5 & 6 & 37.5 & 3 & 18.75 & 22.0 & 100.0 \\
\hline 4 & Sodong & 7.0 & 28.0 & 1.0 & 6.3 & 2 & 12.5 & 10 & 62.5 & 5 & 31.25 & 25.0 & 100.0 \\
\hline 5 & Ngledoksari & 9.0 & 56.3 & 5.0 & 31.3 & 0 & 0 & 2 & 12.5 & 0 & 0 & 16.0 & 100.0 \\
\hline & Jumlah & 43.0 & 46.2 & 10.0 & 10.8 & 4.0 & 4.3 & 19.0 & 20.4 & 17 & 18.3 & 93.0 & 100.0 \\
\hline
\end{tabular}

Berdasarkan jumlah anggota keluarga, sebagian besar keluarga responden terdiri dari 3 sampai 4 orang $(58 \%)$, diikuti oleh jumlah anggota keluarga 5 sampai 6 orang (24\%), 14\% keluarga terdiri dari 1 sampai 2 orang, dan sisanya (4\%) terdiri lebih dari 6 orang. Sebagian besar responden (70\%) mempunyai rumah tipe permanen, 17\% mempunyai rumah semi permanen dan $13 \%$ responden mempunyai rumah non-permanen. Hasil tabulasi berkaitan dengan pengalaman responden dalam menghadapi longsor, sebanyak 50\% responden pernah mengalami bencana longsor lebih dari dua kali, 24\% responden pernah mengalami bencana longsor sebanyak dua kali dan $26 \%$ responden berpengalaman menghadapi bencana longsor sebanyak satu kali. Banyaknya responden yang pernah mengalami kejadian longsor sebanyak lebih dua kali menunjukkan bahwa masyarakat telah terbiasa menghadapi bencana longsor dan kesadaran terhadap program mitigasi bencana sangat tinggi.

\section{B. Strategi Coping Masyarakat}

Masyarakat Tawangmangu memiliki pengetahuan lokal yang diwariskan secara turun-temurun dalam mengantisipasi kejadian bencana longsor dengan berbagai strategi coping, baik yang bersifat struktural (fisik) maupun yang bersifat nonstruktural (non-fisik). Menurut Twigg (2004), strategi coping didefinisikan sebagai implementasi atau penerapan pengetahuan lokal masyarakat yang didapatkan secara turun temurun dalam menghadapi bencana alam dan bencana lainnya. Menurut
Heryanti (2012), strategi coping didefinisikan sebagai kebiasaan atau perilaku masyarakat dalam upaya mengurangi resiko terjadinya bencana dan mengurangi dampak yang timbul akibat bencana.

Strategi coping masyarakat lokal dalam menghadapi bencana dapat dibagi menjadi empat macam, yaitu strategi coping ekonomi, struktural, sosial dan kultural (Twigg, 2004). Berdasarkan tata waktu pelaksanaannya, strategi coping dapat dilakukan sebelum terjadinya bencana, selama terjadi bencana dan sesudah bencana. Berikut ini adalah berbagai strategi coping yang dilakukan masyarakat Kecamatan Tawangmangu dalam menghadapi longsor:

\section{Strategi coping ekonomi :}

Strategi coping ekonomi masyarakat adalah pengerahan sumber daya ekonomi yang dimiliki masyarakat, baik secara individu maupun kelompok, yang lebih difokuskan dalam mendapatkan sumber penghasilan lain diluar pekerjaan utamanya untuk mendapatkan tambahan penghasilan. Benson dan Clay (2004) menyatakan bahwa, kunci keberhasilan untuk meminimalisasi dampak bencana adalah kecepatan dalam merespon dampak bencana yang sangat tergantung pada kondisi ketahanan ekonomi masyarakat di wilayah yang terkena bencana. Tujuan utama strategi coping ekonomi adalah untuk meningkatkan ketahanan ekonomi agar ketika terjadi bencana masyarakat masih dapat mencukupi kebutuhannya.

Beberapa strategi coping ekonomi yang dilakukan masyarakat di lokasi penelitian adalah : 
a. Membentuk kelompok Arisan pada setiap RT (Rukun Tetangga). Forum ini juga digunakan sebagai ajang silaturahim dan merencanakan kegiatan gotong-royong terutama dalam menghadapi bencana longsor. Selain itu, forum ini juga sering digunakan sebagai media sosialisasi dari pihak pemerintah lokal (desa) berkaitan dengan program yang akan dilaksanakan dalam menghadapi longsor.

b. Mendirikan koperasi sebagai wadah bagi masyarakat untuk menabung dan meminjam uang jika kebutuhan mendesak. Dalam keadaan bencana, peranan koperasi sangat besar dalam memberikan bantuan pinjaman modal. Sebagai contoh, ketika bencana longsor menimpa tanah pertanian maka dengan bantuan koperasi masyarakat dapat kembali menanam. Mayoritas masyarakat Tawangmangu bekerja sebagai petani dengan hasil pertanian utama adalah sayur-sayuran misalnya kentang, wortel, dan kol.

c. Melakukan kerja sampingan diluar pekerjaan utama sebagai petani, misalnya pedagang bunga atau mendirikan toko sederhana yang menjual kebutuhan rumah tangga. Hal tersebut dilakukan untuk menambah penghasilan dan tabungan keluarga. Jika sewaktu-waktu terjadi bencana longsor yang menimpa lahan pertanian, dengan tabungan yang dimiliki, masyarakat dapat segera melakukan usaha-usaha perbaikan dan pemulihan.

\section{Strategi coping struktural}

Strategi coping struktural difokuskan dalam pembangunan yang bersifat fisik dan aplikasi teknologi yang bertujuan untuk mengurangi kerugian akibat longsor dan meminimalisasi resiko terjadinya bencana longsor. Beberapa strategi coping struktural yang dilakukan masyarakat diantaranya adalah :

a. Memasang bronjong kawat dan dinding penguat dari batu pada tebing sungai atau di tepi kiri dan kanan jalan yang berlereng curam.

b. Memperkuat konstruksi jalan dengan bahan beton, membangun saluran air dengan menggunakan material beton, dan memperkuat bangunan rumah dengan konstruksi beton.

c. Bergotong-royong untuk menutup retakanretakan pada tanah, terutama menjelang musim penghujan.

d. Membangun dan menyiapkan tempat evakuasi bagi korban bencana, seperti masjid, balai desa, dan sekolah. e. Membangun dan memperbaiki fasilitas publik yang rusak karena longsor, misalnya pos ronda, saluran air, pos kesehatan, dan jalan

f. Membangun terasering pada lahan pertanian dengan kelerengan tinggi, dan menerapkan sistem pertanian tumpang sari tanaman sengon dan tanaman sayur.

g. Menyokong rumah dengan menggunakan bambu atau kayu agar tidak roboh. Strategi ini digunakan oleh sebagian masyarakat Dusun Guyon yang rumahnya miring karena adanya gerakan tanah.

\section{Strategi coping sosial}

Strategi coping sosial difokuskan pada kegiatan sosial, misalnya gotong-royong dan kegiatan lain yang bersifat berkelompok, seperti mengadakan pertemuan warga untuk membahas kegiatan yang akan dilakukan dalam mengantisipasi bencana longsor. Kegiatan ronda malam pada musim hujan merupakan salah satu strategi coping sosial yang dilakukan untuk mengantisipasi terjadinya longsor. Berikut ini adalah beberapa contoh strategi coping sosial yang dilakukan masyarakat di lokasi penelitian.

a. Melakukan penanaman pohon di sepanjang tepi sungai dan pada areal yang rawan terhadap longsor.

b. Melaksanakan pertemuan sebelum datangnya musim hujan untuk merencanakan kegiatan dalam rangka mengantisipasi longsor.

c. Mengadakan pengajian rutin tiap malam Jum'at untuk menjaga kondisi psikologis warga.

d. Pada musim hujan dilaksanakan ronda malam, terutama di daerah dengan tingkat kerawanan longsor tinggi.

e. Bergotong royong saling membantu masyarakat yang terkena musibah longsor, dengan mempersiapkan tempat evakuasi sementara, meminta bantuan pada pihak terkait, dan menyebarkan informasi kepada warga lain.

f. Bersama-sama membersihkan material longsor dan memperbaiki rumah dan bangunan yang rusak akibat longsor.

\section{Strategi coping kultural:}

Strategi coping kultural merupakan penerapan kearifan lokal masyarakat yang telah diwariskan secara turun-temurun dari generasi ke generasi, yang merupakan salah satu cara agar terhindar dari bencana longsor. Salah satu contoh strategi coping kultural yang dilakukan masyarakat Kecamatan Tawangmangu adalah melaksanakan upacara tradisional yang disebut 
dengan "Ruwahan" dan "Suroan". Upacara Ruwahan biasanya dilaksanakan pada hari Selasa Kliwon Bulan Ruwah sedangkan upacara Suroan dilaksanakan pada malam tanggal satu Bulan Suromenurut penanggalan Jawa. Kedua jenis upacara tradisional tersebut dilaksanakan dengan maksud agar diberikan hasil panen yang melimpah dan terhindar dari bencana. Beberapa contoh dokumentasi strategi coping yang dilakukan masyarakat Tawangmangu dapat dilihat pada Gambar 1, 2, 3, dan Gambar 4.

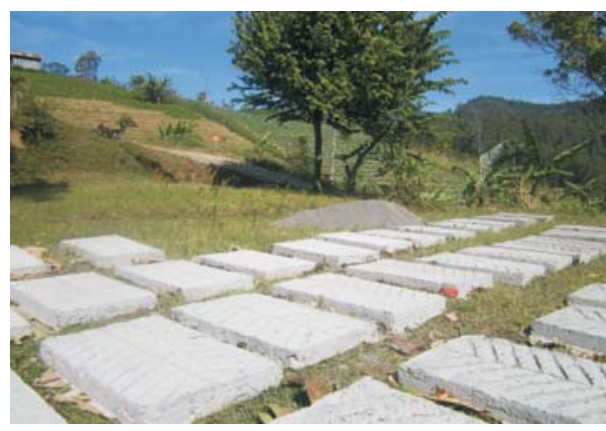

Gambar (Figure) 1

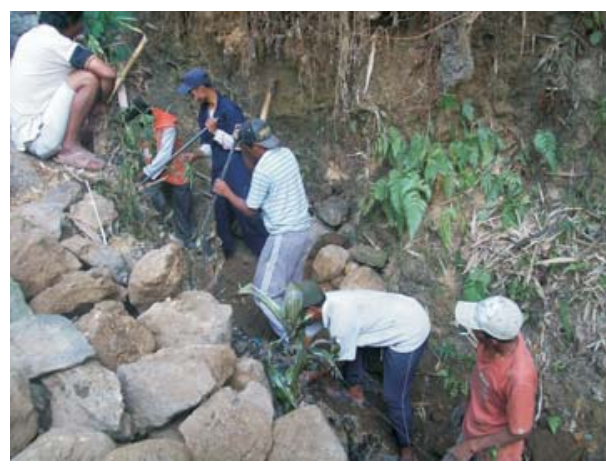

Gambar (Figure) 2

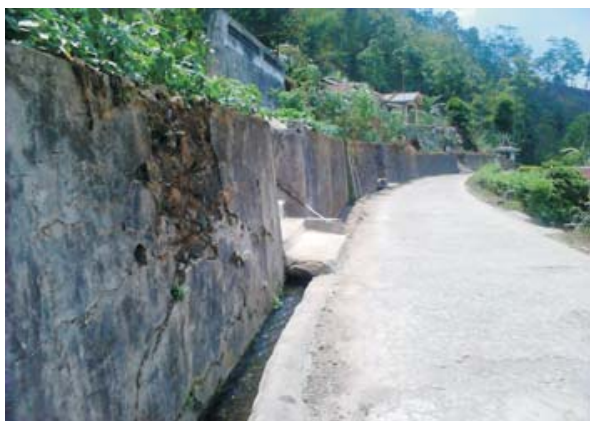

Gambar (Figure) 3

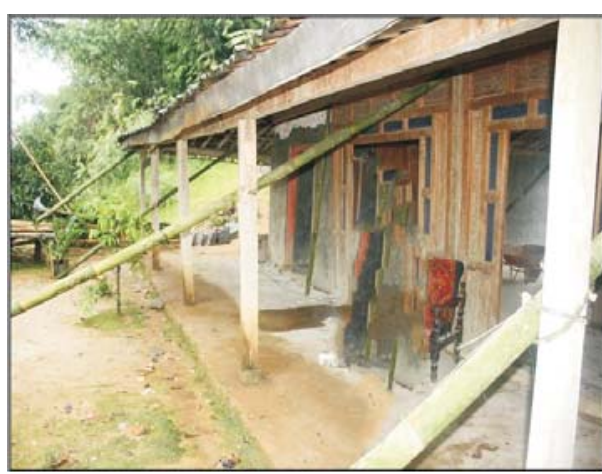

Gambar (Figure) 4

Gambar 1. Pembangunan jalan dengan konstruksi beton

Figure 1. Roadconstruction using concrete materials

Gambar 2. Pembangunan saluran air secara bergotong royong

Figure 2. Construction of water channels with mutual help method

Gambar 3. Pembangunan tebing beton disisi jalan

Figure 3. Construction of retaining wall on steep slope at road side

Gambar 4. Menyokong rumah menggunakan bambu agar tidak roboh

Figure 4. Supporting the house usingbamboo to avoidcollapse

\section{Tingkat Kapasitas Masyarakat}

Kapasitas masyarakat terhadap bencana tanah longsor merupakan tingkat kemampuan masyarakat, baik secara individu maupun sosial dalam menghadapi bencana tanah longsor, yang sewaktu-waktu dapat mengancam kehidupan. Dalam penelitian ini, tingkat kapasitas masyarakat dibedakan menjadi tiga tingkatan, yaitu: rendah, sedang dan tinggi. Indikator yang digunakan untuk menilai tingkat kapasitas masyarakat dalam menghadapi longsor adalah akumulasi dari jawaban kuesioner dan wawancara dengan responden. Hasil penjumlahan skor dari akumulasi jawaban responden dengan menggunakan skala Linkert diperoleh nilai minimal 27, nilai maksimal 55 dan nilai rata-rata 44 poin. Selanjutnya selisih nilai maksimal dan minimaldibagi menjadi 3 kelas berdasarkan nilai interval untukmendapatkan 3 tingkatan kapasitas masyarakat. Berdasarkan hasil perhitungan, kapasitas rendah berada pada interval nilai 27-34, 
kapasitas sedang dengan nilai 35-45 dan kapasitas tinggi dengan nilai 46-55 poin. Masyarakat dengan tingkat kapasitas tinggi memiliki tingkat kesiapsiagaan yang tinggi jika terjadi bencana, sehingga dapat meminimalisasi dampak negatif jika terjadi longsor. Gambar 5 menunjukkan grafik tingkat kapasitas masyarakat pada masing-masing dusun.

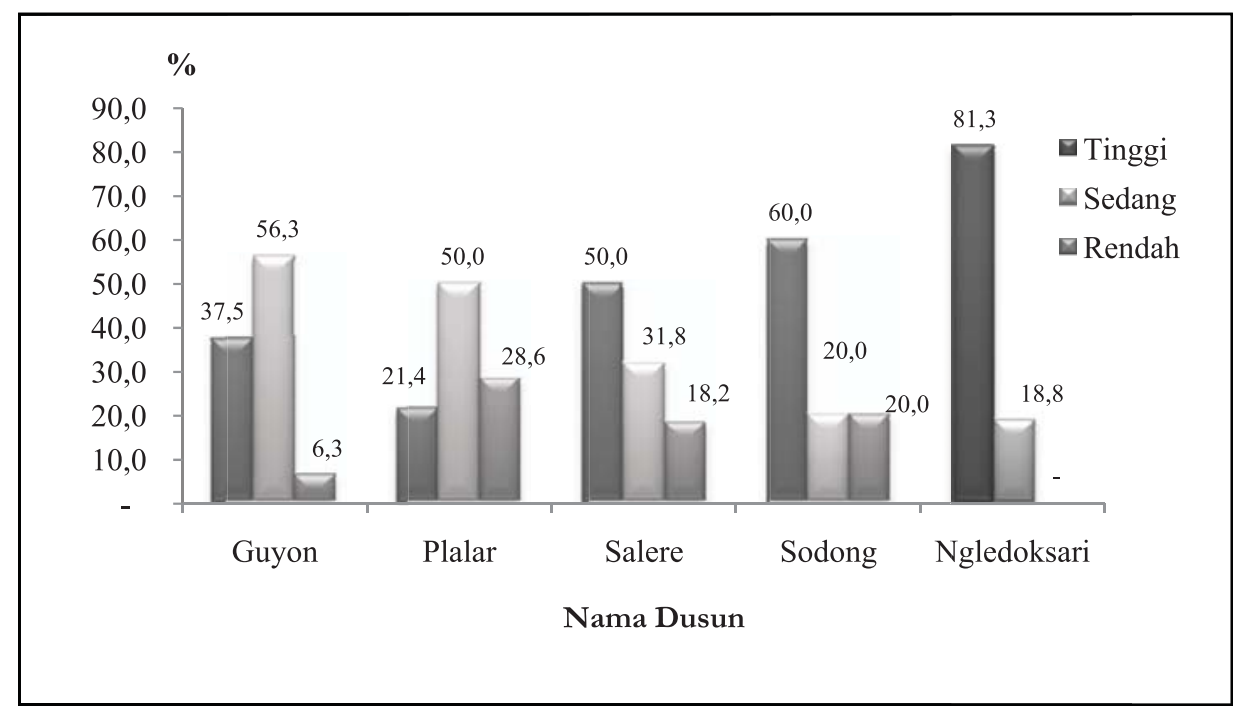

Gambar 5. Tingkat kapasitas masyarakat dalam menghadapi bencana longsor di masing-masing dusun Figure 5. The capacity level of community on coping strategy related landslide at each sub-villages

Tingkat kapasitas masyarakat dalam menghadapi bencana longsor didominasi oleh tingkat tinggi dan sedang. Secara keseluruhan 51,6\% responden mempunyai tingkat kapasitas tinggi, 33,3\% responden mempunyai tingkat kapasitas sedang, dan $15,1 \%$ responden mempunyai tingkat kapasitas rendah.

Pada Gambar 5 dapat dilihat tingkat kapasitas responden pada masing-masing dusun. Responden yang berdomisili di Dusun Ngledoksari sebanyak $81,3 \%$ mempunyai tingkat kapasitas tinggi, responden di Dusun Guyon sebanyak 56,3\% mempunyai tingkat kapasitas sedang, dan responden di Dusun Plalar sebanyak 28,6\% mempunyai tingkat kapasitas rendah.

Masyarakat di Dusun Ngledoksari mempunyai tingkat kapasitas tinggi, artinya memiliki tingkat kesiapsiagaan yang tinggi dalam menghadapi bencana longsor. Pada tahun 2007 di Dusun Ngledoksari terjadi bencana longsor yang menewaskan 34 orang warga. Berdasarkan pengalaman tersebut, masyarakat berusaha meningkatkan kapasitasnya untuk menghindari dampak negatif yang timbul akibat longsor di masa mendatang. Sedangkan masyarakat di Dusun Plalar memiliki tingkat kesiapsiagaan yang rendah, artinya perlu dilakukan usaha-usaha untuk meningkatkan kapasitas masyarakat, baik dalam bidang ekonomi, struktural dan sosial untuk meminimalisasi kerugian jika terjadi bencana. Untuk mengetahui tingkat signifikansi perbedaan tingkat kapasitas di masing-masing dusun digunakan analisis statistik dengan metode chi-square. Hipotesis awal $\left(\mathrm{H}_{0}\right)$ yang digunakan adalah tidak ada perbedaan yang nyata antara tingkat kapasitas pada masing-masing dusun. Hasil analisis chi-square dengan menggunakan perangkat lunak SPSS 19 disajikan pada Tabel 3 .

Berdasarkan Tabel 3 dapat diketahui bahwa nilai Asymp. Sig. (2-sided) adalah 0.024 atau kurang dari 0,05 . Hal ini menyatakan bahwa terdapat perbedaan yang signifikan tingkat kapasitas masyarakat di masing-masing dusun. Dengan menggunakan chi-square hitung juga dihasilkan kesimpulan yang sama, yaitu chi-square hitung $(17,701)$ lebih besar dari pada nilai chi-square tabel $(15,507)$ pada taraf kepercayaan $05 \%$ dan derajat bebas (df) 8. Nilai chi-square hitung lebih besar dari pada chi-square tabel, menunjukkan hipotesis awal $\left(\mathrm{H}_{0}\right)$ ditolak yang berarti terdapat perbedaan yang nyata tingkat kapasitas masyarakat pada masingmasing dusun. 
Tabel 3. Hasil analisis chi-square tingkat kapasitas masyarakat

Table 3. Result of Chi-square analysis of community capacity

\begin{tabular}{|c|c|c|c|}
\hline \multicolumn{4}{|c|}{ Chi-square Tests } \\
\hline & Value & $\mathrm{df}$ & Asymp. Sig. (2-sided) \\
\hline Pearson Chi-Square & $17.701^{\mathrm{a}}$ & 8 & .024 \\
\hline Likelihood Ratio & 20.112 & 8 & .010 \\
\hline Linear-by-Linear Association & 5.914 & 1 & .015 \\
\hline $\mathrm{N}$ of Valid Cases & 93 & & \\
\hline
\end{tabular}

a. 6 cells $(40.0 \%)$ bave expected count less than 5. The minimum expected count is 2.11 .

\section{Faktor yang Mempengaruhi Tingkat Kapasitas Masyarakat}

Beberapa faktor yang diasumsikan berpengaruh terhadap tingkat kapasitas masyarakat dalam menghadapi bencana longsor adalah umur, jenis kelamin, tingkat pendidikan, pekerjaan, penghasilan, jumlah anggota keluarga, tipe rumah, dan pengalaman menghadapi kejadian longsor. Faktor-faktor tersebut merupakan variabel bebas, sedangkan tingkat kapasitas masyarakat merupakan variabel terikat. Untuk mengetahui faktor-faktor yang mempunyai hubungan dengan tingkat kapasitas masyarakat maka dilakukan analisis korelasi. Analisis korelasi merupakan salah satu teknik analisis dalam statistik yang digunakan untuk mengukur keeratan hubungan antara dua variabel atau lebih. Hipotesis awal $\left(\mathrm{H}_{0}\right)$ yang digunakan adalah tidak terdapat korelasi antara variabel bebas dan variabel terikat. Hasil analisis korelasi dapat dilihat pada Tabel 4.

Tabel 4. Analisis korelasi kapasitas masyarakat terhadap longsor

Table 4. Correlation analysis of community capacity related to landslide

\begin{tabular}{lc}
\hline \multicolumn{1}{c}{ Correlations } \\
\hline Umur (Age) & Sig. (1-tailed) \\
\hline Jenis kelamin (Gender) & .000 \\
Tingkat pendidikan (Education) & .000 \\
Mata pencaharian (Occupation) & .000 \\
Tingkat penghasilan (Income) & .389 \\
Jumlah anggota keluarga (Household size) & .000 \\
Tipe rumah (Building type) & .063 \\
Pengalaman menghadapi bencana longsor (Landslide experience) & .000 \\
\hline
\end{tabular}

Pengambilan keputusan didasarkan pada perbandingan antara nilai Sig. (1-tailed) dan nilai probabilitas $(0,05)$. Jika nilai Sig. (1-tailed) lebih kecil dari 0,05 maka hipotesis awal ditolak artinya terdapat hubungan yang erat antara variabel bebas dan variabel terikat. Dari Tabel 4 dapat diketahui bahwa terdapat 6 (enam) variabel yang memiliki nilai Sig. (1-tailed) kurang dari 0,05 yaitu umur, jenis kelamin, tingkat pendidikan, jumlah penghasilan, tipe rumah, dan pengalaman menghadapi bencana longsor. Dengan demikian, dapat disimpulkan bahwa faktor umur, jenis kelamin, tingkat pendidikan, jumlah penghasilan, tipe rumah dan pengalaman menghadapi bencana longsor mempunyai tingkat korelasi yang tinggi dengan tingkat kapasitas masyarakat dalam menghadapi longsor.

Analisis regresi linear berganda digunakan untuk mengetahui faktor-faktor yang berpengaruh terhadap tingkat kapasitas masyarakat dalam 
menghadapi bencana longsor. Hipotesis awal $\left(\mathrm{H}_{0}\right)$ yang digunakan adalah variabel bebas tidak berpengaruh terhadap variabel terikat. Hasil analisis regresi linear berganda dengan menggunakan perangkat lunak SPSS dapat dilihat pada Tabel 5.

Pengambilan keputusan menggunakan T-test dengan nilai probabilitas 0,05 menyatakan bahwa jika nilai signifikansi (Sig.) lebih kecil dari 0,05 maka hipotesis awal $\left(\mathrm{H}_{0}\right)$ ditolak, artinya terdapat pengaruh yang nyata antara variabel bebas dan variabel terikat. Berdasarkan Table 5, dapat dilihat bahwa terdapat tiga variabel yang mempunyai nilai signifikansi kurang dari 0,05 yaitu tingkat pendidikan, jumlah penghasilan, dan tipe rumah. Jadi dapat disimpulkan bahwa faktor tingkat pendidikan, jumlah penghasilan, dan tipe rumah berpengaruh nyata terhadap tingkat kapasitas masyarakat dalam menghadapi bencana longsor. Untuk mengetahui respon ketiga variabel tersebut dapat dilihat pada nilai konstanta (Unstandardized Beta Coefficients). Faktor jumlah penghasilan dan tingkat pendidikan mempunyai nilai konstanta positif yang berarti, semakin tinggi tingkat pendidikan dan penghasilan, akan semakin tinggi pula tingkat kapasitasnya. Konstanta pada variabel tipe rumah bernilai negatif yang berarti, penduduk dengan tipe rumah permanen mempunyai tingkat kapasitas lebih tinggi jika dibandingkan dengan penduduk yang mempunyai tipe rumah nonpermanen atau semi permanen.

Tabel 5. Analisis regresi linear tingkat kapasitas masyarakat terhadap longsor

Table 5. Linear regression analysis of people capacity related to landslide

\begin{tabular}{|c|c|c|c|c|c|}
\hline \multicolumn{6}{|c|}{ Coefficients $^{a}$} \\
\hline \multirow[t]{2}{*}{ Model } & \multicolumn{2}{|c|}{$\begin{array}{l}\text { Unstandardized } \\
\text { Coefficients }\end{array}$} & \multirow{2}{*}{$\begin{array}{c}\text { Standardized } \\
\text { Coefficients }\end{array}$} & \multirow[t]{2}{*}{$\mathrm{t}$} & \multirow[t]{2}{*}{ Sig. } \\
\hline & $\mathrm{B}$ & Std. Error & & & \\
\hline (Constant) & 2.625 & .368 & & 7.140 & .000 \\
\hline Umur (Age) & .004 & .045 & .007 & .100 & .920 \\
\hline Jenis kelamin (Gender) & -.096 & .109 & -.061 & -.879 & .382 \\
\hline Tingkat pendidikan (Education) & .195 & .063 & .248 & 3.116 & .003 \\
\hline Mata pencaharian (Occupation) & -.032 & .030 & -.071 & -1.067 & .289 \\
\hline Tingkat penghasilan (Income) & .366 & .106 & .250 & 3.455 & .001 \\
\hline Jumlah anggota keluarga (Household size) & .047 & .060 & .047 & .793 & .430 \\
\hline Tipe rumah (Building type) & -.511 & .088 & -.497 & -5.823 & .000 \\
\hline $\begin{array}{l}\text { Pengalaman menghadapi bencana } \\
\text { longsor (Landslide experience) }\end{array}$ & -.098 & .054 & -.113 & -1.829 & .071 \\
\hline a. Dependent Variable: Capacity_level & & & & & \\
\hline
\end{tabular}

\section{KESIMPULAN DAN SARAN}

\section{A. Kesimpulan}

Masyarakat Kecamatan Tawangmangu yang tinggal di daerah rawan longsor menerapkan empat jenis strategi coping dalam menghadapi bencana longsor, yaitu strategi coping ekonomi, struktural, sosial, dan kultural. Tingkat kapasitas masyarakat dalam menghadapi bencana longsor berbeda-beda. Secara umum, tingkat kapasitas masyarakat Kecamatan Tawangmangu dalam menghadapi longsor berada pada tingkat sedang hingga tinggi. Semakin tinggi tingkat kapasitas maka akan semakin kecil resiko dampak negatif yang ditimbulkan oleh bencana longsor. Tingkat kapasitas masyarakat dalam menghadapi longsor dipengaruhi oleh tingkat pendidikan, tingkat penghasilan dan tipe rumah.

\section{B. Saran}

Masyarakat Tawangmangu secara turuntemurun menerapkan berbagai strategi coping 
untuk meminimalisasi resiko dan dampak terjadinya longsor. Akan tetapi korban dan kerugian akibat bencana longsor masih sering diderita oleh masyarakat di kawasan ini. Untuk itu diperlukan peran pemerintah dan stakeholder lainnya untuk melengkapi strategi coping yang telah dilakukan masyarakat, terutama strategi coping struktural yang memerlukan biaya besar, contohnya pemasangan bronjong kawat pada tepi sungai dan jalan yang curam, pembangunan penguat tebing dari beton dan pembuatan saluran air permanen. Penguatan kapasitas masyarakat dalam menghadapi longsor terutama pada masyarakat di Dusun Plalar, dapat dilakukan oleh pemerintah dengan instansi terkait dengan cara melaksanakan serangkaian program kegiatan agar tingkat kapasitasnya semakin meningkat. Dengan tingkat kapasitas yang tinggi, resiko jumlah kerugian akibat bencana longsor dapat diminimalisasi.

\section{DAFTAR PUSTAKA}

Albaum, G. (1997). The likert scale revisited: An alternate version. Journal of the Market Research Society, 39(2), 331-348.

Benson, C., \& Clay, E.J. (2004). Understanding the economic and financial impact of natural disaster. Washington D.C. : The world bank.

BNPB (Badan Nasional Penanggulangan Bencana). (2013). Indonesian disaster data and information. Retrieved from http://www.dibi.bnpb.go.id.

BPBD (Badan Penanggulangan Bencana Daerah) Kabupaten Karanganyar. (2012). Rekapitulasi Kejadian Bencana di Kabuapten Karanganyar Tabun 2011. Karanganyar: BPBD Karanganyar.

BPS (Badan Pusat Statistik) Kabupaten Karanganyar. (2012). Tawangmangu dalam angka Tahun 2011. Tawangmangu: Badan Pusat Statistik Kabupaten Karanganyar.

UN-ISDR (United Nation secretariat of the International Strategy for Disaster Reduction). (2004). Living with risk: A global review of disaster reduction initiatives. Geneva: UN Publications.
Hadmoko, D.S., Lavigne, F., Sartohadi, J., Hadi, P., \& Winaryo. (2010). Landslide hazard and risk assessment and their application in risk management and landuse planning in eastern flank of Menoreh Mountains, Yogyakarta Province, Indonesia. Natural Hazards Journal, 54(3), 623642.

Heryanti, D.N. (2012). Community based approach to assess flood risk perception and coping mechanism along code river, yogyakarta municipality. Enschede: University of Twente Faculty of Geo-Information and Earth Observation.

Karnawati, D., Syamsul, M., Teuku, F., \& Wahyu, W. (2012). Development of socio-technical approach for landslide mitigation and risk reduction program in Indonesia. Retrieved from http://www.seed-net.org/download/C11_Paper3.pdf.

Prawiradisastra, S. (2008). Analisis morphologi dan geologi bencana tanah longsor di Desa Ledoksari Kabupaten Karanganyar. Jurnal Sains dan Teknologi Indonesia, 10(2), 84-89.

Sare, M.Y.W. (2009). Tingkat kerentanan dan kapasitas masyarakat lokal terbadap bencana tanah longsor di Kecamatan Kokap, Kabupaten Kulon Progo. Yogyakarta: Sekolah Pascasarjana Universitas Gadjahmada.

Sugiyono. (2007). Metode penelitian kuantitatifkualitatif dan research development. Bandung: Alfabeta.

Sutikno. (1994). Pendekatan geomorfologi untuk mitigasi bencana alam akibat gerakan massa tanah/batuan. Yogyakarta: Fakultas Geografi Universitas Gadjahmada dan Badan Koordinasi Nasional Penanggulangan Bencana.

Twigg, J. (2004). Disaster Risk Reduction: mitigation and preparedness in development and emergency programming: Humanitarian practice network. London: Humanitarian Practice Network, Overseas Development Institute.

Wati, S.E., Hastuta, T., Widjojo, S., \& Pinem, F. (2010). Landslide susceptibility mapping with heuristic approach in mountainous area; A case study in Tawangmangu Sub 
District, Central Java, Indonesia. International Archives of the Photogrammetry, Remote Sensing and Spatial Information Science, 38(8), 248-253 .
Yani, A.S. (1997). Analisis konsep koping: Suatu pengantar. Jurnal Keperawatan Indonesia, I (1), $1-5$. 